out of 17 patients presented head and neck, breast, or cervical carcinomas in addition to lymphoma. Moreover, an increased incidence of lung cancer has been reported in patients with sarcoidosis. ${ }^{2}$

It has been suggested that the increased mitotic activity and dysregulation of lymphocytes observed in sarcoidosis, increases the risk of mutation. ${ }^{3}$ These factors, in addition to steroid treatment, may favour the development

1 Brincker $\mathrm{H}$. Coexistence of sarcoidosis and malignant disease: causality or coincidence? Sarcoidosis 1989; 61: 3143.

2 Brincker $H$, Wilbek $E$. The incidence of malignant tumours in patients with respiratory sarcoidosis. $\mathrm{Br} \mathcal{F}$ Cancer 1974; 29: 24751.

3 Brincker $\mathrm{H}$. The sarcoidosis-lymphoma syndrome. $\mathrm{Br} \mathcal{F}$ Cancer 1986; 54: 46773.

Romer FK. Sarcoidosis and cancer. N Engl f Med 1982; 306: 1490.

5 McInerney PD. Sarcoidosis and lymphoma: is there an association? Postgrad Med $\mathcal{F} 1986 ; 62: 809$.

6 Masuda R, Toyoshima H, Bandou T, Isoyama T, Matsui Y, Takemura T. Malignant lymphoma of the stomach associated with systemic sarcoidosis. Cancer 1992; 70: 25926. of lymphoma. The pathogenic explanation for the existence of a second epithelial tumour is more complex. One could speculate that the depletion of circulating T4 lymphocytes and decreased resistance to oncogenic viruses might lead to decreased tumour rejection in the epithelia exposed to carcinogenic stimuli.

We thank Dr Miguel Yebra for a critical review of the manuscript.

7 Finke R, Lydtin H, Prechtel K. Sarcoidosis and immunocytoma. Am $\mathcal{F}$ Med 1986; 80: 93942.

8 Genestie C, Guettier C, Raphael M, et al. Sarcoidosis and non-Hodgkin lymphoma. A non-fortuitous association. Ann Pathol 1994; 14: 1203.

9 Harris NL, Jaffe ES, Stein $\mathrm{H}$, et al. A revised EuropeanAmerican classification of lymphoid neoplasms: a proposal from the International Lymphoma Study Group. Blood 1994; 84: 136192.

10 Brenan NJ, Fennelly J, Towers RP, Fitzgerald MX Sarcoidosis and lymphoma in the same patient. Postgrad Med f 1983; 59: 5815.

\title{
Renal cell carcinoma with solitary metastases appearing during 18 years of follow-up
}

\author{
M Siekierska-Hellmann, K Sworczak, A Lewczuk, K Błaut, E Boj
}

\begin{abstract}
Summary
We present a case of renal cell carcinoma with solitary metastases to the thyroid, the post-nephrectomy scar and the lungs, appearing during an 18-year period following nephrectomy.
\end{abstract}

Keywords: renal cell carcinoma, solitary metastases, diagnostic difficulties

Renal cell carcinoma is a disease with an elusive course. The absence of characteristic symptoms frequently delays the diagnosis. The classical 'diagnostic triad': haematuria, flank pain and abdominal mass, occurs only in 10$15 \%$ of patients, with $47 \%$ possibly having distant metastases at the time of diagnosis. ${ }^{1,2}$ Even with no metastases in $30 \%$ of patients, renal cell carcinoma presents multiple general symptoms such as fever, haematuria, polycythaemia, increased erythyrocyte sedimentation rate (ESR), weight loss, hypertension and hypercalcaemia. ${ }^{2}$ However, in $20 \%$ of cases renal cell carcinoma may have an asymptomatic course and may be discovered either incidentally or at autopsy. In 1-3\% the first symptoms appear as isolated distant metastases which, following surgery, give a $35 \%$ chance for a five-year survival. Solitary metastases of renal cell carcinoma to the lungs, ${ }^{3}$ pituitary, ${ }^{4}$ small intestine, ${ }^{5}$ thyroid, ${ }^{6,7}$ supraclavicular lymph nodes, neck region ${ }^{8}$ and skin $^{9,10}$ have been reported.

We present a patient with renal cell carcinoma with solitary metastases appearing during an 18-year period following nephrectomy.

\section{Case report}

A 49-year-old woman was admitted in 1974 for haematuria. Apart from that, she was asymptomatic and physical examination, laboratory tests, and chest X-ray were normal. ESR was $20 \mathrm{~mm} / \mathrm{h}$. Urography revealed an irregular lateral margin of the left kidney and displaced upper and lower calyces.

Renal arteriography confirmed the presence of a tumour in the middle part of the left kidney. In January 1975 nephrectomy was performed through the twelfth bed of the rib. The left kidney was excised with an orangesized tumour. No renal vessels invasion or the enlargement of surrounding lymph nodes were observed. Histopathological examination showed a tumour of $4 \times 4 \mathrm{~cm}$, the mass being yellowish-grey with blood extravasation. Microscopic examination demonstrated a renal cell carcinoma with no vessel invasion. She was discharged symptom-free and no complaints were reported in the following 10-year period. In March 1985 she noted a thyroid enlarge- 
Figure 1 Metastasis of thyroid gland. Histopathological examination. renal carcinoma to the HE original $100 x$

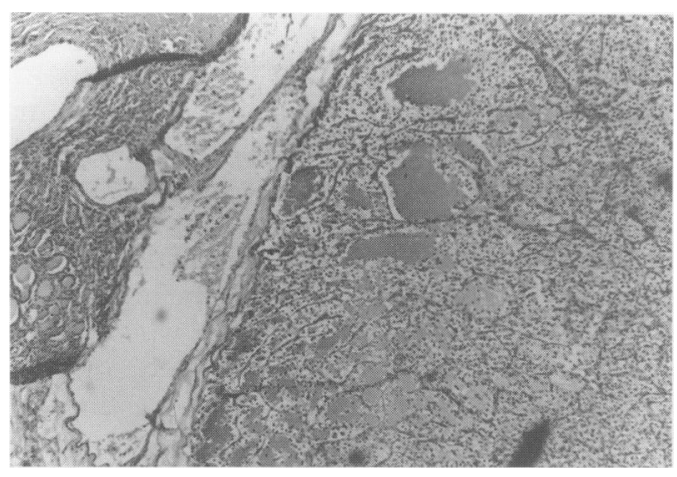

\begin{tabular}{|l|}
\hline Learning points \\
\hline - long dormancy is a notable feature of renal cell \\
carcinoma with $11 \%$ of patients surviving more \\
than 10 years having late recurrences \\
- the thyroid and the skin are less frequent sites \\
of solitary metastases of renal cell carcinoma \\
- histopathological evaluation of metastases to \\
the thyroid is difficult and the new staining \\
techniques may be helpful \\
- cutaneous metastases offer poor prognosis \\
because, when diagnosed, other organs are \\
metastasised in $30 \%$ of patients
\end{tabular}

Figure 2 Metastasis of renal carcinoma to the post-nephrectomy scar. Histopathological examination. HE original $100 \times$

chest X-ray were without abnormalities. Abdominal ultrasonography revealed the liver to be free of metastases, with no local recurrence. A solid tumour involving both cutaneous and subcutaneous tissues with no muscle penetra-

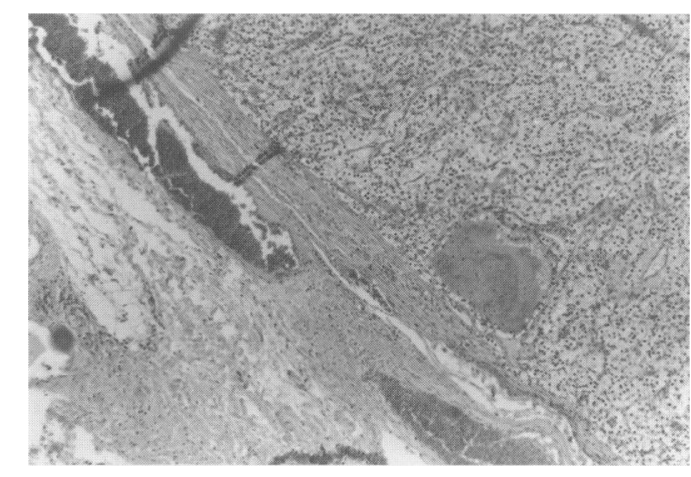

ment. Palpation revealed a hard, smooth, painless node of the left thyroid lobe, nonmovable on swallowing. The right lobe was normal and the lymphatic nodes were not enlarged. The blood count was normal, ESR $12 \mathrm{~mm} / \mathrm{h}$, serum thyroxine was $102 \mathrm{nmol} / \mathrm{l}$ and no antithyroid antibodies were found. Chest $\mathrm{X}$-ray revealed no abnormalities in the lungs and some left and back trachea displacement. Scintigraphy showed a 'cold' tumour. Fineneedle aspiration cytology revealed a follicular tumour. The patient was qualified for surgery and a distinctly separated tumour was removed from the left thyroid lobe. Intra-operatively, follicular thyroid carcinoma was diagnosed histologically. Total thyroidectomy was performed. Macroscopic examination showed a left thyroid lobe of $8 \times 5 \times 4 \mathrm{~cm}$, cherry-red in cross section with cherry-yellow foci, quite distinctly separated from its surroundings. Postoperative examination revealed renal cell carcinoma metastasis to the thyroid $\left(\mathrm{I}^{\circ}\right.$ of histological malignancy) (figure 1). Urography was performed to reveal the left post-nephrectomy status and to confirm that the right kidney was normal. She was administered substitutive doses of L-thyroxine and for seven years neither local recurrence nor other distant metastases were noticed.

In 1992, the patient noticed a small, soft nodule in the region of the post-nephrectomy scar. As the lesion increased in size her temperature became irregular and there was a $7 \mathrm{~kg}$ weight loss. She was re-admitted in February 1993. On examination, skin and mucous pallor were observed and a bluishred, fixed, fist-sized tumour was found in the left nephrectomy scar. Haemoglobin was $8.2 \mathrm{~g} / \mathrm{dl}$, ESR $140 \mathrm{~mm} / \mathrm{h}$, serum creatinine and tion was removed surgically. Histopathological examination revealed a metastasis of the renal cell carcinoma to subcutaneous tissue (figure 2). She remained well for three months, staying afebrile, with ESR lowered and the complete blood count improved. In 1994 she was admitted again for fever, anaemia and increased ESR. Chest X-ray was normal but computed tomography showed two foci of metastases, $1 \mathrm{~cm}$ in diameter, in the posterior diaphragmatic-costal region of both lungs, a $2.5 \times 1.8 \mathrm{~cm}$ tumour in segment 10 of the left lung, and enlarged left hilus lymphatic nodes. The multiple metastases made another operation impossible. Symptomatic treatment and medroxy-progesterone $500 \mathrm{mg}$ intramuscularly twice a week was instituted. The patient died of respiratory insufficiency. Autopsy was not performed.

\section{Discussion}

An atypical course of renal cell carcinoma causes numerous diagnostic difficulties..$^{1,2,6-8}$ About $25 \%$ of patients already have metastases at diagnosis. The most frequent distant metastatic sites are the lungs, bones and central nervous system. The liver, thyroid, skin and soft tissues are less frequent. ${ }^{11}$ Secondary carcinomas comprise only $0.5 \%$ of all thyroid tumours, $70 \%$ of which are caused by renal cell carcinoma and metastases may appear many years after the excision of primary focus. It is unclear how isolated metastases to the thyroid appear without affecting the lungs. ${ }^{\text {? }}$

Cutaneous metastases form $2.8-4.4 \%$ of skin malignant carcinomas. ${ }^{9}$ About $6 \%$ are caused by renal cell carcinomas. ${ }^{9}$ The lesion is usually solitary, smooth, pinkish-red and may suggest a mild lesion, similar to granuloma or may have the appearance of a cutaneous horn. Metastases to the nephrectomy scar have been reported, our patient being another example. Naturally, the iatrogenic implantation of renal cell carcinoma cells during the operation 17 years earlier cannot be excluded. The mechanism of the long dormancy of this carcinoma, is particularly interesting and still unexplained. ${ }^{5}$

Tumour size correlates with metastatic potential and its incidence increases consider- 
ably for tumours with a diameter of over $5 \mathrm{~cm} \cdot{ }^{1,12}$ With no renal capsule infiltration, a five-year survival period was noted in $60 \%$. Other unfavourable prognostic factors of renal cell carcinoma include the presence of metastases at first diagnosis, lymphatic gland involvement and the presence of general symptoms. ${ }^{13}$ In our patient, the only unfavourable prognostic factor was the tumour size.

Even an untreated renal cell carcinoma may present a very slow growth. The survival of non-operated patients has been reported as being up to eight years. ${ }^{1}$ Spontaneous stabilization of the tumour may occur in up to $20 \%$ of patients. ${ }^{10}$ There are also reports of spontaneous regression of metastases after excision of the primary focus. ${ }^{1}$ Once metastases appear, the further course of the disease is difficult to predict. At that stage the patient survival used to be a matter of months rather than years. Our patient lived eight years after the excision of the first solitary metastasis to the thyroid, which manifested 10 years after the operation of the primary renal cell carcinoma focus.

Favourable survival factors are: length of asymptomatic period between nephrectomy and the appearance of the first metastasis,

1 Cronin RE, Kaehny WD, Miller PD, et al. Renal cell carcinoma: unusual systemic manifestations. Medicine 1976; 55: $291-311$.

2 Chisholm GD, Roy RR. The systemic effects of malignant renal tumors. Br F Urol 1971; 43: 687-700.

3 Whitesell PL, Peters SG. Pulmonary manifestations of extrathoracic malignant lesions. Mayo Clin Proc 1993; 68: $483-91$

4 Weiss RE, Corvalan AH, Dillon RW. Metastatic renal cell carcinoma presenting as impotence. $\mathcal{F}$ Urol 1993; 149: 821 3.

5 Toh SKC, Hale JE. Late presentation of a solitary metastasis of renal cell carcinoma as an obstructive duodenal mass. Postgrad Med f 1996; 72: 178-9.

6 Fabbro SD, Monari G, Barbazza R. A thyroid metastasis revealing an occult renal clear-cell carcinoma. Tumori 1987; 73: $187-91$.

7 Sworczak K, Mizan K, Szaach E. Solitary metastasis to the thyroid of the clarocellular renal cancer. Pol Arch Med Wew 1990; 84: $30-5$. the patient's performance at diagnosis, limited lung metastases and the excision of the primary focus. ${ }^{10}$ The surgical excision of a solitary, distant metastasis gives a five-year survival in $34 \%$ but the probability of other metastases increases. Their location seems to have some influence on the survival period and response to treatment. Cutaneous metastases offer a poor prognosis because when diagnosed other organs are metastasized in $30 \%$ of patients. Another difficulty we encountered was in the histopathological diagnosis of the metastasis to the thyroid. Fine-needle aspiration cytology and intra-operative examination suggested follicular thyroid carcinoma. Similar difficulties have been described by others. PAS staining and immunocytochemical examination may prove helpful in histopathological evaluation. ${ }^{6,7,14}$

Due to the development of screening techniques renal cell carcinoma is diagnosed earlier and at a less severe state of disease advance. The length of survival has been increased because of aggressive surgical treatment to eliminate distant metastases, as well as hormonal and interferon therapy.

8 Kiely JM. Hypernephroma. The internist's - tumor. Med Clin North Am 1966; 50: $1067-83$.

9 White JW. Evaluating cancer metastatic to the skin. Geriatrics 1985; 40: $67-73$.

10 Maldazys JD, De Kernion JB. Prognostic factors in metastatic renal carcinoma. F Urol 1986; 136: $376-9$

11 Sternberg StS. Diagnostic surgical pathology. New York: Raven Press, 1994; p 1711

12 Targoński PV, Frank W, Stuhldreher D, Guinan PD. Value of tumor size in predicting survival from renal cell carcinoma among tumors, nodes and metastases stage 1 and stage 2 patients. $\mathcal{F}$ Urol 1994; 152: 1389-92.

13 Bretheau D, Lechevallier E, Eghazarian C, Grisoni V, Coulange C. Prognostic significance of incidental renal cell carcinoma. Eur Urol 1995; 27: 319-23.

14 Salech H, Masood S, Wynn G, Assaf N. Unsuspected metastatic renal cell carcinoma diagnosed by fine needle aspiration biopsy. A report of 4 cases with immunocytochemical contributions. Acta Cytol 1994; 38: 554-61. 